\title{
Impacto territorial del autoempleo en la economía social en España
}

\section{María del Carmen Pérez González y Lidia Valiente Palma}

\section{RESUMEN}

En el presente trabajo se plantea como objeto de estudio identificar el distinto comportamiento seguido por las Comunidades Autónomas en cuanto al autoempleo generado en el ámbito de la Economía Social estableciendo, en su caso, un patrón de comportamiento según la situación económica de cada territorio. Se realiza un análisis cluster, incorporando variables que relacionan el territorio y la Economía Social, incidiendo en los años 2007 (previo a la crisis) y 2013. Entre los resultados hay que destacar la distinta evolución que han seguido las Comunidades Autónomas en el periodo objeto de estudio que se debe, en buena parte, al diferente tratamiento concedido al sector desde el marco institucional y a las características específicas de cada territorio.

PALABRAS CLAVE: Desarrollo territorial, economía social, empresas de participación, cooperativas, autónomos, análisis cluster.

CLAVES ECONLIT: J540, P130, R100.

Cómo citar este artículo: PÉREZ, M.C. \& VALIENTE, L. (2015): "Impacto territorial del autoempleo en la economía social en España", CIRIEC-España, Revista de Economía Pública, Social y Cooperativa, 83, 83-114.

Correspondencia: María del Carmen Pérez González y Lidia Valiente Palma, Universidad de Cádiz.

E-mail de contacto: valientepalma@gmail.com. 


\section{Impact territorial du travail indépendant sur l'économie sociale en Espagne}

RÉSUMÉ : Cet article a pour objet d'étude l'identification du comportement de chaque Communauté autonome en ce qui concerne le travail indépendant généré dans le secteur de l'économie sociale et d'établir, le cas échéant, un schéma de comportement selon la situation économique de chaque territoire. Une analyse de classification est réalisée en incorporant des variables faisant le lien entre le territoire et l'économie sociale et en se focalisant sur les années 2007 (avant la crise) et 2013. Parmi les résultats, il faut souligner l'évolution différente de chaque Communauté autonome lors de la période étudiée qui est due, en grande partie, aux différents traitements appliqués au secteur par le cadre institutionnel et aux caractéristiques spécifiques de chaque territoire.

MOTS CLÉ : Développement territorial, économie sociale, entreprises de participation, coopératives, indépendants, analyse de classification.

\section{Self-employment in the social economy: an approach to its territorial evolution in Spain}

ABSTRACT: The objective of this study was to identify the different behaviors of the Autonomous Communities of Spain regarding self-employment generated in the sphere of the Social Economy, and to attempt to establish behavior patterns according to the economic situation of each region. A cluster analysis was performed, incorporating variables that relate the territory and the Social Economy and focusing on the years 2007 (before the crisis) and 2013. Differences in the evolution of the Autonomous Communities for the period under review are among the main results, and are due largely to differences in the sector's treatment by the institutional framework and to the specific characteristics of each territory.

KEY WORDS: Territorial development, social economy, labor-managed firms, cooperatives, self-employment, cluster analysis. 


\section{1.- Introducción}

En España la repercusión negativa de la crisis sobre el empleo y la producción ha provocado una reducción del PIB per cápita del 1,5\% y un aumento de la tasa de paro de alrededor del $217 \%$, según datos del Instituto Nacional de Estadística (INE) ${ }^{1}$, con respecto a años previos.

Estos efectos son diferentes por Comunidades Autónomas (CC.AA.), según la realidad previa a la llegada de la recesión y la respuesta dada por los elementos y los agentes territoriales en cada una de las regiones. Ante tal situación hay que destacar el papel de la Economía Social por su capacidad para crear empleo en general y sobre los colectivos con riesgo de exclusión en particular, por su actuación respecto a los dos grandes sectores institucionales (público y privado), así como por el conjunto de valores, principios y características que determinan su importante aportación al desarrollo endógeno territorial sostenible.

Se considera muy importante determinar el papel del autoempleo generado por estas entidades, entendiéndolas como empresas de Economía Social (Barea, 2003), en una situación de crisis que está teniendo efectos muy negativos sobre el empleo con un carácter diferencial respecto a otros países europeos.

A partir de esto, el objetivo general de este trabajo es identificar el diferente comportamiento de las CC.AA. con respecto al autoempleo generado por la Economía Social, tanto colectivo (representado por los autónomos en cooperativas, por su importancia en el sector), como individual (a partir de los autónomos propiamente dicho), con especial incidencia en los efectos de la crisis, determinando el grado de resistencia de estas entidades ante las nuevas situaciones surgidas a partir de la recesión económica.

Por ello, tras plantear la evolución del autoempleo en Economía Social a nivel nacional para el periodo 1999-2013, se realiza, en primer lugar, un análisis de la evolución de las CC.AA. en cuanto al PIB per cápita y al desempleo como indicadores de su situación económica y de una primera aproximación al grado de desarrollo territorial; $y$, posteriormente, se profundiza en la respuesta de esas comunidades a la problemática de la destrucción de empleo, en concreto, del autoempleo tanto colectivo como individual de la Economía Social. Para desarrollar esto, se aplica un análisis cluster a cada uno de los perfiles establecidos incorporando el marco territorial a la Economía Social.

1.- Calculado a partir de la Contabilidad Nacional de España y de la Encuesta de Población Activa para los años 2007 y 2013. 
La estructura del trabajo, tras esta introducción, es la siguiente:

En primer lugar, se establece un marco teórico donde se relaciona la Economía Social y el autoempleo y, posteriormente, con el Desarrollo Territorial; así como también se hace referencia a trabajos significativos que ponen en evidencia una mayor resistencia del empleo en las empresas de Economía Social ante situaciones de crisis. En segundo lugar, se expone la metodología a seguir y, tras esto, se realizan los análisis clusters a nivel de CC.AA. Finalmente se establecen las conclusiones más importantes derivadas de este estudio.

A partir del análisis aplicado y del estudio realizado, se pone de manifiesto el comportamiento diferencial según la situación territorial específica, tanto en lo que se refiere a los efectos de la crisis como en cuanto a su respuesta mediante el autoempleo en entidades de Economía Social, no pudiéndose establecer patrones de comportamiento homogéneos entre las distintas regiones. Esto podría ser una evidencia de la necesidad de abordar y diseñar políticas y líneas estratégicas para la dinamización del desarrollo territorial sostenible "desde abajo", teniendo en cuenta los recursos endógenos de cada territorio, entre ellos los vinculados con la Economía Social.

\section{2.- Autoempleo y Economía Social: una apuesta hacia el Desarrollo Territorial}

La crisis económica actual está teniendo importantes repercusiones negativas sobre la producción, el empleo y la generación y distribución de riquezas, entre otros aspectos. La caída de la demanda, de la actividad económica y la destrucción del tejido empresarial han incidido, en el caso español, de manera más sensible que en el resto de países europeos sobre un mercado laboral con importantes problemas estructurales, entre los que destaca la incapacidad para generar empleo sobre todo en los segmentos sociales formados por jóvenes y mujeres, los más afectados ante la situación de crisis.

En este sentido, el autoempleo, tanto colectivo como individual, se está considerando como una alternativa progresivamente más significativa que puede dar respuesta, aunque no siempre duradera, a las nuevas situaciones surgidas a partir de la recesión económica.

De las diferentes definiciones de autoempleo dadas por organismos públicos y privados, así como por investigadores del tema, se coincide con Cruz y Torres ${ }^{2}$ (2003) al establecer que el autoempleo es "la puesta en marcha de una actividad económica, por una o varias personas, con el objeto fun- 
damental de conseguir con ello una ocupación o puesto de trabajo, siendo precisamente el trabajo su principal aportación e interés en la empresa" (García, 2002: 19). Ahora bien, se hace necesario establecer una relación entre el autoempleo y la Economía Social.

En primer lugar, este autoempleo está vinculado a la Economía Social a través de alguna de sus formas jurídicas: Cooperativas, Sociedades Laborales o Trabajadores Autónomos propiamente dichos, entre otras (Conferencia Europea Permanente de Cooperativas, Mutualidades, Asociaciones y Fundaciones, 2002) $)^{3}$.

En segundo lugar, no todos los trabajadores de estas formas jurídicas son considerados autoempleados ya que, alguna de ellas, cuenta con trabajadores asalariados. Por tanto, es importante señalar que el autoempleo en Economía Social será aquél en el que sus trabajadores sean protagonistas de empresas de participación definidas como "las organizaciones empresariales de la denominada economía social en la que los empresarios lo son con base en su presencia protagonista en el proceso de producción y/o distribución; de manera que su presencia en la financiación no les confiere condición protagonista" (García-Gutiérrez y Fernández, 2005: p.209, a partir de García-Gutiérrez y Lejarriaga, 1996).

Dentro de la Economía Social son de destacar las empresas de trabajo asociado, -las más representativas del autoempleo colectiv0 ${ }^{4}$-, consideradas empresas de participación y recibiendo tal denominación debido a la ya aludida condición de socio-trabajador que adquieren sus protagonistas (Lejarriaga, Bel y Martín, 2013), por la participación activa que tienen en el proceso productivo de la empresa (García-Gutiérrez et al., 2013). Estas empresas necesitan para su constitución de al menos tres socios trabajadores, que llevarán a cabo su actuación en la organización a través de procesos cooperativos y democráticos, y por ello se considera que son organizaciones que surgen a partir del autoempleo colectivo (Melián y Campos, 2010).

Ahora bien, ¿por qué considerar a los trabajadores autónomos como empresas de participación? El empresario individual no tiene por qué participar en el proceso productivo para ser considerado como tal, pero para que sea tratado como empresa de participación, es decir, para que esté considerado dentro del ámbito de la Economía Social, éste es un requisito necesario. Además, hay que señalar que, en España, la mayoría de estos autónomos no cuenta con ningún trabajador asalariado a cargo siendo estos trabajadores autónomos los que participan en los procesos productivos. Esta sería la justificación de considerarlos como empresas de participación (García-Gutiérrez y Fernández, 2005) y por tanto, agentes de la Economía Social.

3.- Carta de principios economía social en: http://www.cepes.es, consultado el 13-06-2014.

4.- Según los últimos datos disponibles del MEYSS, a 31 de diciembre de 2013, alrededor del 54\% del total de empresas cooperativas eran de trabajo asociado. 
La necesidad de buscar una alternativa al desempleo, sobre todo al de carácter estructural, unido a los numerosos trabajos que manifiestan la mayor resistencia de la Economía Social ante situaciones difíciles, otorgan al autoempleo,-a las empresas de participación-, un papel relevante en la actual coyuntura económica.

En lo que respecta a los trabajos que analizan esta mayor resistencia, como se recoge en Calderón y Calderón (2012), pueden destacarse tanto de autores nacionales (Tomás-Carpi, 1997; Grávalos y Pomares, 2001; Díaz y Marcuello, 2010) como internacionales (Guerreri, Nazzaro y Zevi, 1992; Cornforth y Thomas, 1995; Informe CECOP-CICOPA, 2011). Éstos ponen de manifiesto que la Economía Social en general y, las cooperativas en particular, tienen una mayor resistencia a la destrucción del empleo ante una fase de recesión económica, e incluso llegando a presentar en ocasiones un comportamiento contracíclico. Según estos autores, las entidades de Economía Social se muestran más resistentes, proporcionando empleos con menor sensibilidad ante variaciones en el ciclo económico que el resto de empresas.

Las características, principios y valores de las empresas de Economía Social (Chaves, Monzón, Pérez de Uralde y Radrigán, 2013) también repercuten en la respuesta que estas entidades dan ante los nuevos escenarios derivados de la situación de crisis económica. La importancia de la persona sobre el capital, la responsabilidad interna y externa (Monzón, 2006; Barea, 1990, Barea, 2008; Carta de Principios de la Economía Social, de la Conferencia Europea Permanente de Cooperativas, Mutualidades, Asociaciones y Fundaciones (CEP-CMAF), 20025; Confederación Empresarial Española de la Economía Social -CEPES-6), la generación de autoempleo y/o la implicación personal en el trabajo como un proyecto de vida, implican una mayor resistencia y supervivencia de estas empresas. A su vez, estos principios pueden ser orientadores de un empleo estable y de calidad.

A todo lo anterior hay que añadir un aspecto relevante: la situación socioeconómica derivada de la crisis y la capacidad de respuesta ante ésta no son homogéneas en todos los territorios, que son entendidos no sólo como un espacio físico, sino como un conjunto de interconexiones socioeconómicas, institucionales, históricas, culturales, y/o medioambientales, establecidas a partir de las posibilidades presentes y potenciales de sus recursos endógenos (Vázquez, 1999; Alburquerque, 2007).

El desarrollo de estos territorios, establecido desde abajo, a partir de sus recursos endógenos, se puede concebir como el resultado de la acción de cuatro fuerzas o factores (Vázquez, 2005: 38): "Organización flexible de la producción, Innovación y difusión del conocimiento, Instituciones y Desarrollo Urbano del Territorio". Las entidades de Economía Social como manifestación de emprendimiento que contribuye al sistema productivo local, surgidas desde las propias características territoriales, están vinculadas al entorno por sus propios valores y principios de responsabilidad y solidaridad, ya que parten de su propia realidad y están en gran medida dirigidas hacia ese territorio.

5.- Declaración final común de las organizaciones europeas de Economía Social CEP-CMAF, 20 de junio de 2002.

6. - CEPES-Andalucía: $h$ ttp://www.cepes-andalucia.es/index.php?id=78, consultado el 13-06-2014. 
Es un elemento generador de desarrollo que depende del resto de factores integrados en el territorio, como el marco institucional, el sistema productivo, el tejido empresarial, el nivel de formación, la capacidad de asumir riesgo, el cambio tecnológico o la cultura emprendedora, entre otros.

Por tanto, "Economía Social" y "Territorio" están fuertemente relacionados, y su respuesta a las nuevas situaciones surgidas a partir de la crisis es diferente según las características y las realidades propias de cada marco territorial.

Además, desde el ámbito territorial local, a partir del diseño y aplicación de estrategias locales, puede contribuirse de manera significativa a la consecución del desarrollo sostenible, destacando nuevamente el papel de las entidades de Economía Social en el desarrollo local como elemento participante de estas estrategias, con valores y principios específicos, fomentándose el respeto y el compromiso entre los diferentes agentes del territorio (Tomás-Carpi, 2008).

El ámbito local ofrece posibilidades a la Economía Social y, a la vez, requiere para su desarrollo de la actuación de estas entidades, teniendo en cuenta que la mayor parte de sus proveedores y clientes están vinculados con los mercados locales. Estas empresas, imbricadas en el territorio a nivel interno y, a nivel externo, con otros espacios territoriales, pueden contribuir a la dinamización territorial y al fomento de las interconexiones de los diferentes actores locales, promoviendo la expansión de redes territoriales y su efecto multiplicador.

El binomio "Economía Social - Desarrollo Territorial Sostenible" debería considerarse específicamente en la planificación estratégica, en los procesos de desarrollo endógeno, como una posibilidad factible, presente en los sistemas productivos territoriales y en las estructuras socioeconómicas actuales.

La Economía Social desarrolla un rol muy significativo en la dinamización del territorio, sobre todo por su contribución a la generación de empleo, al desarrollo del emprendimiento y/o a su "compromiso con lo local, con la solución de sus problemas, donde nacen y se desarrollan estas empresas" (De Castro, 2003: 44). Además, puede relacionar y complementar las actuaciones llevadas a cabo por los otros dos grandes sectores institucionales -público y privado- aumentando su valor añadido al desarrollo local y regional (Comité de las Regiones Europeas, 2002).

A todo lo anterior hay que añadir que, la Economía Social, además de contribuir al desarrollo sostenible de los territorios y responder a las nuevas necesidades sociales que van surgiendo en el contexto actual, constituye una fórmula democrática que promueve la integración y la cohesión social (Martín y Lejarriaga, 2011), sobre todo en el contexto actual en el que la globalización está favoreciendo el aumento de las desigualdades sociales (Inglada y Sastre, 2014) y territoriales.

En definitiva, la nueva Economía Social está muy vinculada a lo local y a su capacidad de implicación y compromiso con el empleo y con la consecución de los objetivos del territorio (Sanchis y 
Campos, 2005) y, en especial, en situaciones de crisis, proporcionando un crecimiento y desarrollo sostenible y equilibrado (Melián y Campos, 2010). Esto, unido a los problemas sobre todo estructurales de desempleo, lleva a plantear el autoempleo colectivo y el individual, -a las empresas de participación-, como una alternativa a la situación actual.

\section{3.- Metodología}

En relación a la evolución de la Economía Social respecto a la variación del ciclo económico en España, existen varios trabajos entre los que destacan Díaz (2000), Grávalos y Pomares (2001), Clemente, Díaz y Marcuello (2009), Díaz y Marcuello (2010), Monzón (Coord., 2010), Román (2010), Calderón y Calderón (2012) y Sala, Farré y Torres (2014).

En lo que respecta al análisis del comportamiento de la Economía Social desde el ámbito regional -a nivel de CC.AA.-, de entre los estudios señalados, pueden destacarse los de Grávalos y Pomares (2001), Clemente, Díaz y Marcuello (2009) y Monzón (Coord., 2010). Grávalos y Pomares (2001) plantean una serie de variables macroeconómicas como posibles explicativas de la variación del empleo y del número de empresas cooperativas, a través de un modelo econométrico. Clemente, Díaz y Marcuello (2009) utilizan el análisis de convergencia propuesto por Barro y Sala i Martí, relacionando la contribución de la Economía Social con la reducción de desigualdades en el PIB y en el empleo. En Monzón (Coord., 2010) se analiza la evolución de empresas de Economía Social (cooperativas de trabajo asociado y sociedades laborales) a partir del análisis descriptivo de datos disponibles de fuentes estadísticas y de la elaboración de cuestionarios a empresas del sector. En el primer trabajo, el periodo objeto de estudio comprende desde el año 1986 a 1995; en el segundo, desde 1999 a 2007 y, en el tercero, de 2000 a 2008 (a 2009 en algunos casos).

En el presente trabajo, la Economía Social, y en concreto el autoempleo generado en este ámbito, se realiza a nivel de CC.AA., ampliando en este caso el periodo objeto de estudio y aplicando una nueva metodología.

La idea de estudiar la Economía Social desde una perspectiva territorial se debe a la relación ya aludida en apartados anteriores entre la Economía Social y las características y especificidades territoriales, que pueden influir en la evolución y comportamiento de ésta.

En lo que se refiere a la metodología aquí utilizada, dado que el objeto de estudio consiste en determinar los diferentes comportamientos en cuanto al autoempleo (colectivo e individual) según la situación económica de las CC.AA. españolas, se aplica un análisis cluster empleando el método 
del "vecino más cercano" ya que, esta técnica de análisis exploratorio y basado en interpretaciones de carácter cualitativo, proporciona grupos en los que sus miembros presentan algún grado de similitud entre ellos y, a su vez, permite percibir la diversidad territorial entre éstos.

Dicho análisis se realiza, en primer lugar, para el año 2007, incidiendo en la llegada de la crisis y sus efectos negativos atendiendo a las especificidades territoriales de las diferentes CC.AA. y, posteriormente, para 2013, con la crisis ya más consolidada.

Como variables indicativas de la situación económica de una determinada región se utilizan la "Tasa de Paro" y el "Producto Interior Bruto (PIB) per cápita" a partir de datos del Instituto Nacional de Estadística (INE). Esto permite obtener una aproximación a la situación económica y al nivel de desarrollo de la región.

Para medir el autoempleo se cuenta con las siguientes variables obtenidas de determinadas fuentes secundarias como el Ministerio de Empleo y Seguridad Social (MEYSS) y el Instituto Nacional de Estadística (INE):

- Como indicador para el nivel de autoempleo colectivo, se utiliza el número de trabajadores autónomos en sociedades cooperativas y el número de sociedades cooperativas en las que la plantilla íntegra pertenece al régimen de autónomos (MEYSS), también ponderadas por cada por cada 1000 ocupados totales y por cada 1000 empresas totales, respectivamente.

- Como indicador del autoempleo individual se utiliza la variable número de autónomos propiamente dicho (MEYSS) ponderado por cada 1000 ocupados totales.

En lo que se refiere al número de ocupados totales y número de empresas totales, estos datos han sido tomados de la Encuesta de Población Activa (EPA) y del Directorio Central de Empresas (DIRCE), respectivamente, disponibles en el INE.

Hay que señalar que éste es un análisis que no está exento de limitaciones dada las restricciones que presentan los datos disponibles para la Economía Social. El MEYSS no distingue qué proporción de trabajadores están como asalariados, que aparecen incluidos con el total de trabajadores en cooperativas en el Régimen General de la Seguridad Social, lo que impide determinar aquéllos que son realmente autoempleados y no asalariados.

Dada esta limitación, se han tomado únicamente los trabajadores en cooperativas afiliados al régimen de autónomos y se ha acudido al número de empresas cooperativas cuya plantilla íntegra pertenece a este régimen de autónomos de la Seguridad Social. De esta forma, se puede obtener una mejor aproximación al nivel de autoempleo colectivo y a la dimensión de éste.

A partir de estos datos, se realizan cuatro análisis cluster aplicados a los años 2007 y 2013 , de manera que, como ya se ha señalado, puedan recogerse los efectos de la crisis y la respuesta dada 
por las distintas CC.AA. en materia de autoempleo. En primer lugar, se identifican los diferentes comportamientos de las CC.AA. ante el impacto de la crisis sobre el empleo y la producción; en segundo lugar, se determina la diferente capacidad territorial de la Economía Social como generadora de autoempleo y/o ante el mantenimiento de éste; y por último, se realiza un análisis por separado de los componentes de este autoempleo -colectivo e individual-.

Este estudio se ha realizado analizando estas variables para todas las CC.AA., sin considerar las Ciudades Autónomas de Ceuta y Melilla por su particular situación.

\section{4.- La evolución del autoempleo en Economía Social}

La crisis económica afecta negativamente también al empleo en el ámbito de la Economía Social, tanto al número de trabajadores en cooperativas como al número de autónomos propiamente dicho (Gráfico 1). A partir de 2007, año bisagra hacia la crisis, se aprecia una importante caída en el autoempleo, que podría ser motivada por la destrucción de empleo y/o la disminución en la generación del mismo.

\section{Gráfico 1. Evolución del autoempleo en Economía Social, 1999-20137 (valores absolutos)}

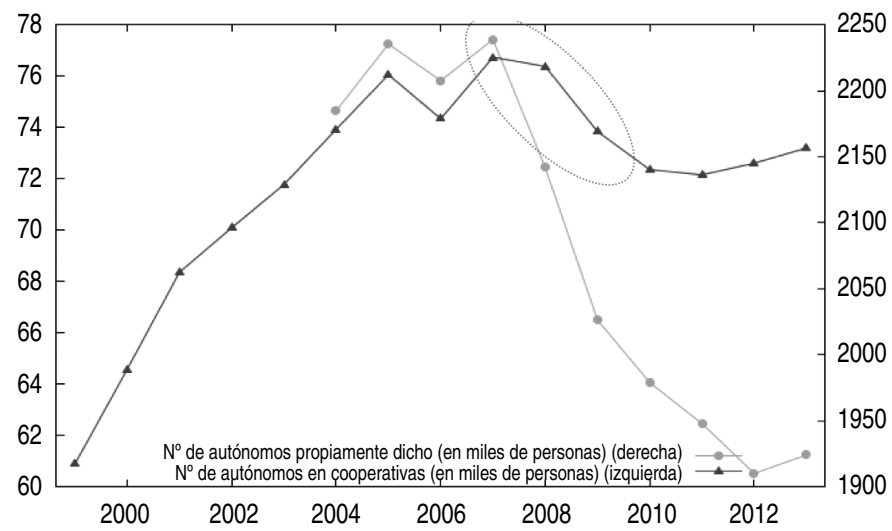

FUENTE: Elaboración propia a partir de datos del MEYSS. 
Un aspecto muy relevante para entender el grado de respuesta de la Economía Social ante las nuevas situaciones derivadas de la crisis, es comparar el impacto de sus efectos sobre el autoempleo en estas entidades respecto a la repercusión que ha tenido esta recesión a nivel de toda la economía española. En este sentido, es de destacar que, si bien en términos absolutos se produce una caída del autoempleo, en términos relativos, al compararla con los ocupados totales, la Economía Social responde de manera menos sensible a la recesión económica, suavizándose el impacto negativo de ésta sobre el desempleo (Gráfico 2).

El cambio de tendencia del comportamiento del autoempleo relativo en Economía Social, es decir, en proporción al número de ocupados totales en la economía en general, es muy significativo, poniéndose en valor la aportación de estas entidades al mantenimiento del empleo y a la amortiguación de las perturbaciones cíclicas.

\section{Gráfico 2. Evolución del autoempleo en Economía Social, 1999-20138 (valores relativos)}

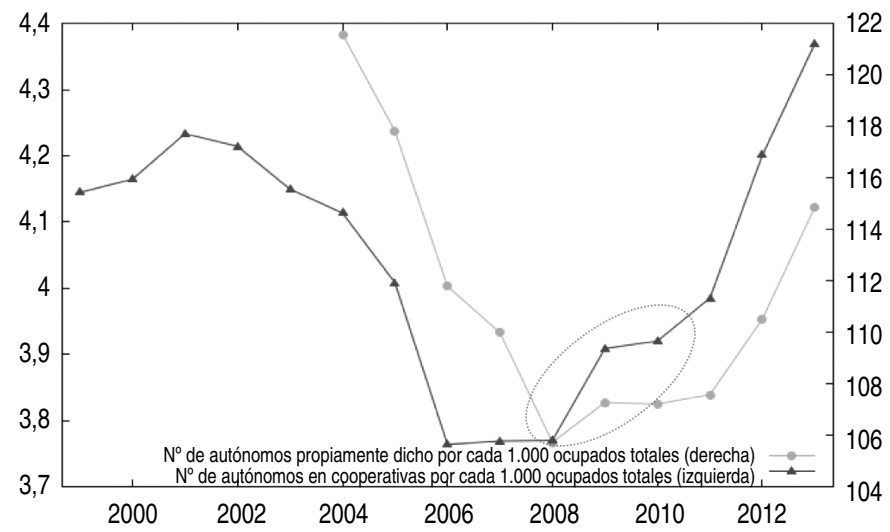

FUENTE: Elaboración propia a partir de datos del MEYSS.

No obstante, no existe un total consenso entre los investigadores acerca de cuál es realmente el comportamiento y qué efectos tiene la respuesta de las entidades de Economía Social respecto al empleo, ante situaciones recesivas: por un lado, hay que destacar el efecto refugio de las cooperativas, con una actuación anticíclica, bien por la transformación de empresas convencionales en empresas de Economía Social, o como respuesta a la situación de desempleo (Grávalos y Pomares, 2001; Calderón y Calderón, 2012); por otro, resisten mejor a la situación de crisis por la mayor flexibilidad de ajuste de la jornada laboral (Calderón y Calderón, 2012). 
En este sentido, Calderón y Calderón (2012: 24) señala que "la crisis económica aumenta el potencial expansivo de las entidades de economía social y su capacidad de generación de empleo".

Por otro lado, el trabajo de Díaz y Marcuello (2010), no ha demostrado un comportamiento anticíclico de las empresas de Economía Social, aunque sí ha puesto de manifiesto una mayor resistencia de estas empresas en situaciones de crisis. Otros autores, como Díaz (2000), consideran que estas empresas pueden constituirse más para mejorar las condiciones laborales de sus trabajadores, como instrumento para mejorar el bienestar socioeconómico de determinados colectivos, que para paliar una situación de desempleo.

En este trabajo se pretende profundizar en el comportamiento de la Economía Social a través del autoempleo, ante la crisis económica actual, teniendo en cuenta las diferencias territoriales derivadas de su impacto sobre el PIB per cápita y la tasa de paro.

Se ha analizado cómo ha repercutido la crisis sobre el autoempleo en la Economía Social, tanto en términos absolutos, como en relación a los ocupados totales en la economía, para determinar su sensibilidad ante las oscilaciones económicas. En este sentido, los datos arrojan lo siguiente:

En cuanto a la caída del autoempleo en valores absolutos:

- Autoempleo colectivo: $-4,9 \%$

- Autoempleo individual: $-14 \%$

En proporción al número de ocupados totales (número de autónomos propiamente dicho, y número de trabajadores autónomos en cooperativas, ambos por cada 1000 ocupados):

- Autoempleo colectivo: $+15,93 \%$

- Autoempleo individual: $+3 \%$

Tanto el autoempleo colectivo como el individual mejoran su proporción con respecto al número total de ocupados; es decir, el autoempleo ha caído en menor medida que el número de ocupados en general -que ha disminuido el 17,71\% en 2013 respecto a 2007-, destacando sobre todo el colectivo.

Por tanto, se puede argumentar que, en períodos de crisis, el autoempleo en el ámbito de la Economía Social es más estable que el empleo total de la economía, bien porque se tiendan a crear estos puestos de trabajo como una medida alternativa a la situación de desempleo, o bien porque estos trabajadores presenten una mayor flexibilización ante la situación, adaptándose mejor a la misma.

Esto ocurre a nivel nacional; pero a nivel territorial, como podrá comprobarse a continuación, no se presenta de manera homogénea entre todas las CC.AA., ni en cuanto a los efectos de la crisis ni en la respuesta a los mismos considerando el autoempleo. 


\section{5.- Las diferencias territoriales en la situación económica y en el nivel de autoempleo en la Economía Social}

En primer lugar se ha realizado el análisis cluster por CC.AA. para agrupar los diferentes comportamientos regionales en base a la situación económica de cada territorio, medida por las variables PIB per cápita y tasa de paro, en los años 2004 (etapa de expansión económica previa a la crisis), 2007 (año bisagra hacia la crisis) y 2013 (con una crisis ya consolidada).

\section{Gráfico 3. Dendograma obtenido para 2004 a partir de las variables "tasa de paro" y "PIB per cápita" de las distintas CC.AA.}

\section{Dendograma}

Método Vecino más Cercano, Euclidean Cuadrado

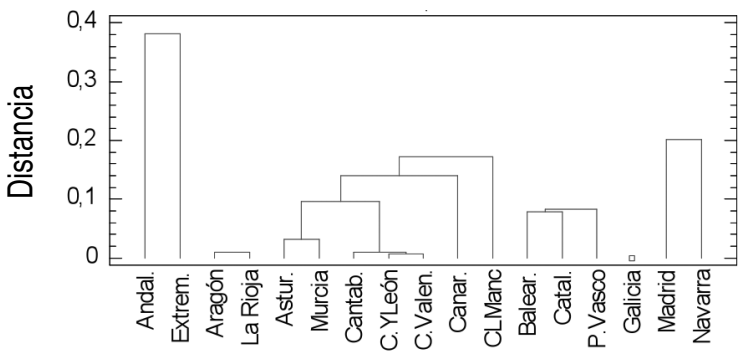

\section{Tabla 1. Resultados cluster 2004. Situación económica de las CC.AA.}

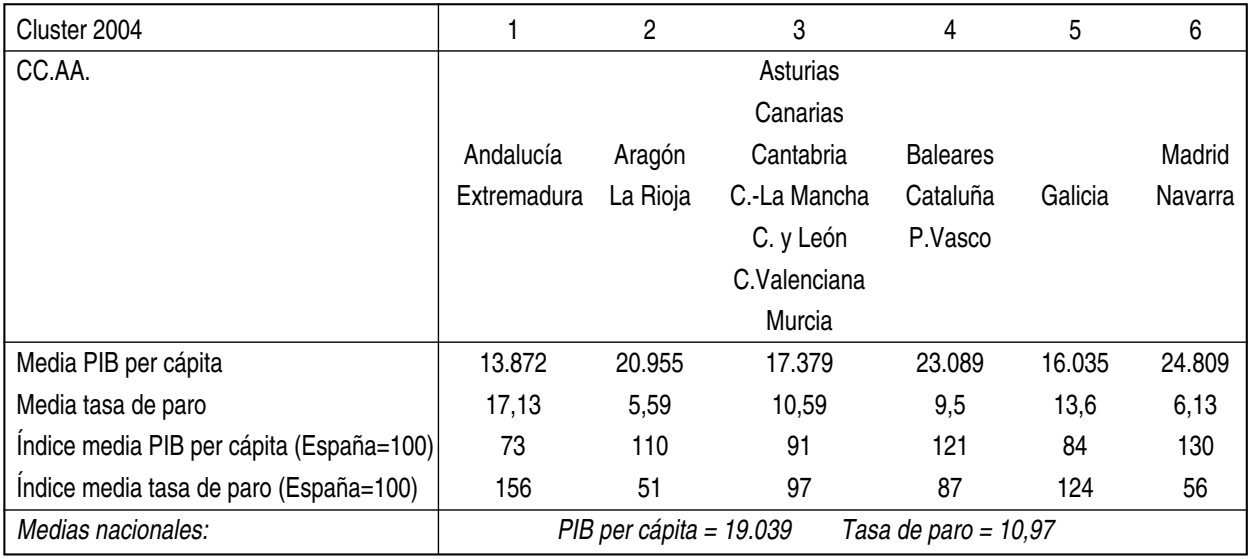

CIRIEC-España, Revista de Economía Pública, Social y Cooperativa 
En relación a la media PIB per cápita y tasa de paro en España para el año 2004 (19.039 euros y un 10,97\% respectivamente), siendo estas variables indicativas del grado de dinamización o situación económica del territorio y, tomándolas como referencias, se puede realizar la siguiente clasificación regional (Tabla 1):

- Territorios con situación económica muy favorable: Madrid y Navarra (cluster 6), con PIB per cápita superior a la media en el 30\% y una tasa de paro de tan sólo el 6,13\% (cuatro puntos porcentuales inferiores a la media).

- Territorios con situación económica favorable: Baleares, Cataluña y País Vasco (cluster 4). Estas comunidades tienen un PIB per cápita superior a la media nacional en un $21 \%$ y la tasa de paro es un $87 \%$ de la de España.

- Territorios con nivel económico medio: Aragón y La Rioja (cluster 2), siendo el PIB per cápita un $21 \%$ superior a la media y contando con una tasa de paro inferior en un $49 \%$.

- Territorios con situación económica baja:

- Galicia (cluster 5), con un PIB per cápita inferior a la media en un $16 \%$ y una tasa de paro elevada (un $24 \%$ superior a la media).

- Asturias, Canarias, Cantabria, Castilla La Mancha, Castilla y León, Comunidad Valenciana y Murcia (cluster 3). Para estas comunidades se ha obtenido una media de grupo de un PIB per cápita que alcanza el 91\% de la media española; sin embargo, la tasa de paro logra situarse por debajo de la media nacional (es un $97 \%$ de la de España), pudiendo ser indicativo de que se tratan de actividades que, aunque generan empleo, producen poco valor añadido.

- Territorios con nivel económico muy bajo: Andalucía y Extremadura, siendo el PIB per cápita tan solo el $73 \%$ del nacional, y situándose la tasa de paro en un $56 \%$ por encima de la de España.

En este año de referencia, se pone de manifiesto la falta de homogeneidad territorial, con importantes divergencias entre las diferentes CC.AA. españolas, incluso dentro de un periodo de expansión económica. Esta situación previa puede condicionar el impacto de la crisis e incluso la capacidad territorial de respuesta, pudiendo identificarse distintas pautas de comportamiento.

Por eso es importante analizar la situación en los momentos de inicio de la crisis (2007) y, posteriormente, bajo los efectos negativos de la misma (2013), identificándose los cambios acontecidos y el grado de respuesta de la Economía Social como generadora (o estabilizadora) de autoempleo, tanto colectivo como individual. 


\section{Gráfico 4. Dendograma obtenido para 2007 a partir de las variables "tasa de paro" y "PIB per cápita" de las distintas CC.A.A.}

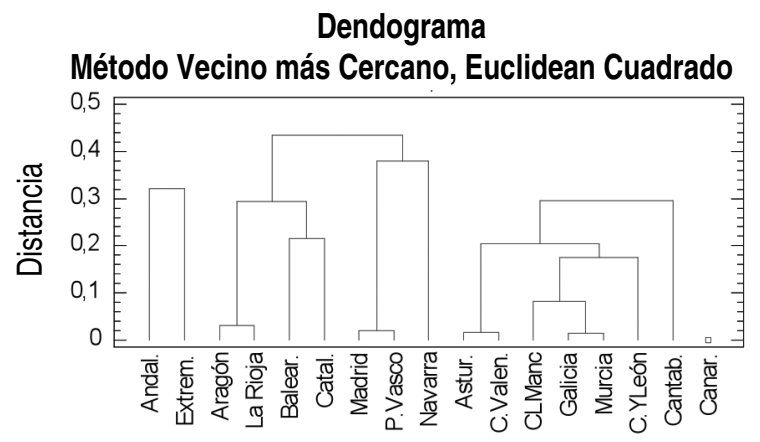

\section{Tabla 2. Resultados cluster 2007. Situación económica de las CC.AA.}

\begin{tabular}{|l|cccc|}
\hline Cluster 2007 & 1 & 2 & 3 & 4 \\
\hline CC.AA. & & Aragón & Asturias & \\
& & La Rioja & Cantabria & \\
& & Baleares & C.-La Mancha & \\
& Andalucía & Cataluña & C.y León & Canarias \\
& Extremadura & Madrid & C.Valenciana & \\
& & P.Vasco & Galicia & \\
& & Navarra & Murcia & \\
\hline Media PIB per cápita & 16.747 & 27.104 & 20.650 & 20.698 \\
Media tasa de paro & 12,91 & 5,94 & 7,59 & 10,44 \\
Índice media PIB per cápita (España=100) & 74 & 120 & 91 & 91 \\
Índice media tasa de paro (España=100) & 156 & 72 & 92 & 126 \\
\hline Medias nacionales: & PIB per cápita $=22.622$ & Tasa de paro $=8,26$ & \\
\hline
\end{tabular}

En lo que respecta a 2007 se ha reducido la diversidad regional, estableciéndose un menor grado de segregación entre los territorios (se han obtenido dos grupos menos que en el 2004). Aunque los valores medios de las variables objeto de estudio mejoran -se incrementa el PIB per cápita en un 19\% y cae la tasa de paro un $25 \%$ - hay que destacar el carácter diferencial que sigue presentando el grupo compuesto por Andalucía y Extremadura con respecto al resto de CC.AA., ya que presenta un atraso relativo muy significativo en las dos variables en este año bisagra, repercutiendo directamente en su evolución y en su posibilidad de salida de la crisis (Tabla 2). 


\section{Gráfico 5. Dendograma obtenido para 2013 a partir de las variables "tasa de paro" y "PIB per cápita" de las distintas C..A.A.}

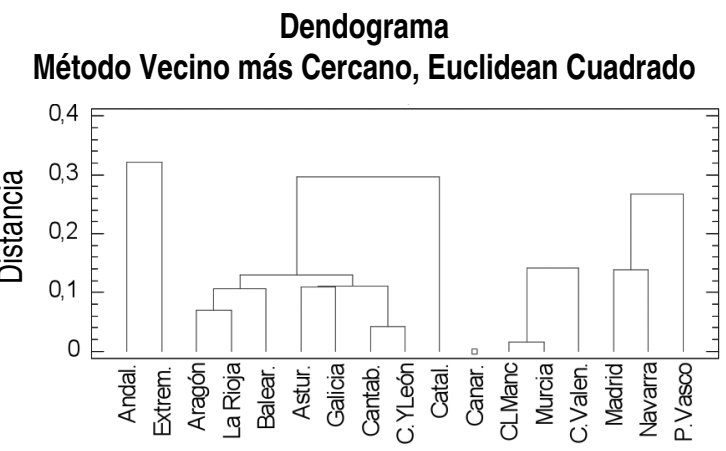

\section{Tabla 3. Resultados cluster 2013. Situación económica de las CC.A.A.}

\begin{tabular}{|c|c|c|c|c|c|}
\hline Cluster 2013 & 1 & 2 & 3 & 4 & 5 \\
\hline CC.AA. & $\begin{array}{c}\text { Andalucía } \\
\text { Extremadura }\end{array}$ & $\begin{array}{c}\text { Aragón } \\
\text { Asturias } \\
\text { Baleares } \\
\text { Cantabria } \\
\text { C.y León } \\
\text { Cataluña } \\
\text { Galicia } \\
\text { La Rioja }\end{array}$ & Canarias & $\begin{array}{c}\text { C.La Mancha } \\
\text { C.Valenciana } \\
\text { Murcia }\end{array}$ & $\begin{array}{l}\text { Madrid } \\
\text { Navarra } \\
\text { P.Vasco }\end{array}$ \\
\hline Media PIB per cápita & 15.846 & 23.068 & 18.873 & 18.394 & 29.077 \\
\hline Media tasa de paro & 35,02 & 21,92 & 34,07 & 29,36 & 18,06 \\
\hline Índice media PIB per cápita (España=100) & 71 & 104 & 85 & 83 & 131 \\
\hline Índice media tasa de paro (España=100) & 133 & 83 & 129 & 111 & 68,51 \\
\hline Medias nacionales: & & r cápita & & de paro $=$ & \\
\hline
\end{tabular}

Los resultados para 2013, con la persistencia de la situación de crisis, muestran que, aunque la caída de los indicadores afecta de manera generalizada a todas las CC.AA. -el PIB per cápita cae un $1,5 \%$ y la tasa de paro se incrementa el $219 \%$, respecto a $2007-$, se agravan las diferencias regionales, con la consecuente dificultad para el diseño y la ejecución de políticas generales. En este sentido, deben tenerse en cuenta y aplicarse, por un lado, medidas globales y, por otro, medidas específicas vinculadas a la realidad territorial presente y potencial de cada región (Tabla 3). 
Se pone de manifiesto que, aunque la crisis afecta a toda la economía española, su impacto territorial es diferente, agudizándose la divergencia regional que ya existía en época de expansión económica. Esto puede producirse por la acción conjunta de la situación previa del territorio antes de la llegada de la recesión económica (mayor precariedad, sistemas productivos más débiles, menor capacidad emprendedora, entre otros) y la capacidad de respuesta para paliar los efectos negativos de la misma a partir de sus recursos endógenos y de otros factores exógenos.

Dado los resultados anteriores y estableciendo una aproximación al grado de desarrollo de las distintas CC.AA. a partir de la situación económica descrita, puede establecerse una clasificación de las mismas según valores de PIB per cápita y tasas de paro, obteniéndose, por un lado, un grupo de comunidades que podrían ser consideradas muy desarrolladas como son Madrid, Navarra, Cataluña o País Vasco; y, por otro, aquéllas que sistemáticamente cuentan con niveles muy bajos como es el caso de Andalucía, Extremadura o Canarias (Gráfico 6).

\section{Gráfico 6. Representación de la aproximación al grado de desarrollo de las CC.AA.9 (2007-2013)}

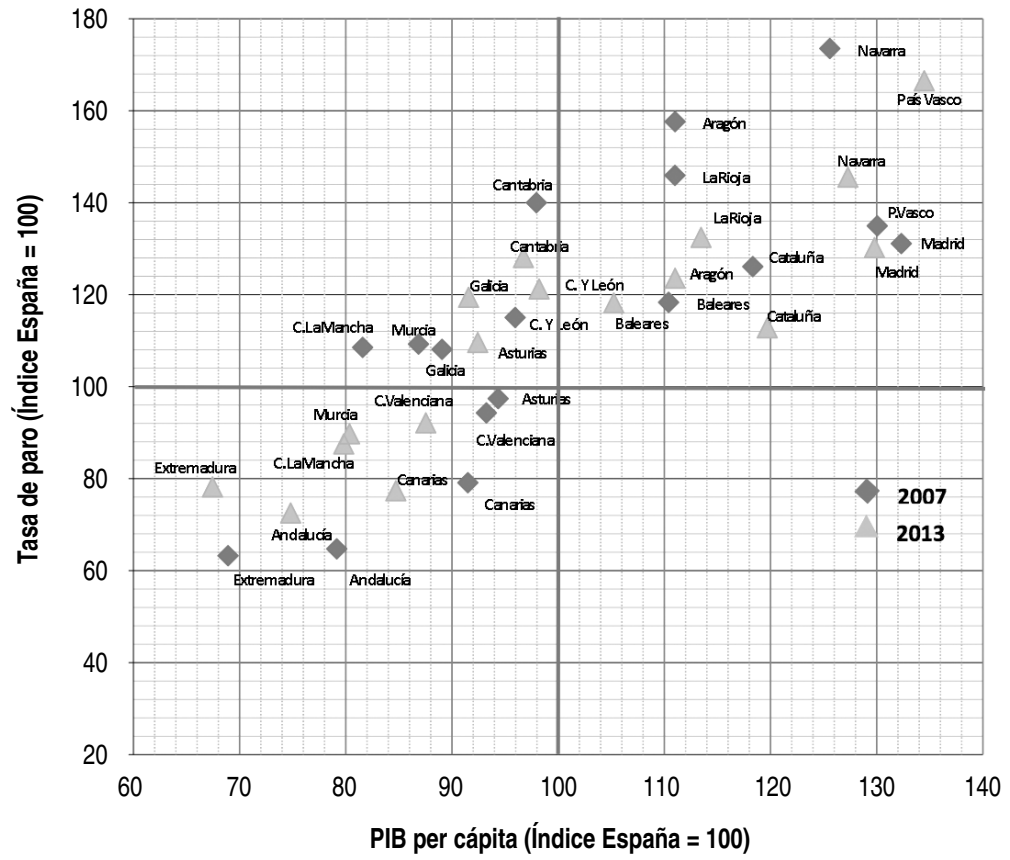

FUENTE: Elaboración propia a partir de datos del INE y MEYSS.

9.- Para el eje de ordenadas se ha tomado la inversa de la tasa de paro, de tal forma que el cuadrante inferior-izquierdo representa a aquellas CC.AA. con las tasas de paro más elevadas. 
Ante la diferente evolución seguida por las CC.AA. españolas con respecto a la crisis y con un problema de desempleo que, aunque de carácter estructural en la economía española, con la recesión actual se ha disparado de manera diferencial respecto a la mayor parte de los países industrializados, las posibilidades de la Economía Social como generadora de autoempleo han cobrado especial interés.

Por ello, a continuación, se analiza la participación de la Economía Social en el autoempleo, por CC.AA., detallando posteriormente la contribución del componente colectivo e individual, para los años 2007 y 2013.

Gráfico 7. Dendograma obtenido para 2007 a partir de las variables "n' autónomos en cooperativas por cada 1.000 ocupados", "n de cooperativas por cada 1.000 empresas" y "n' de autónomos propiamente dicho por cada 1.000 ocupados" de las distintas CC.AA.

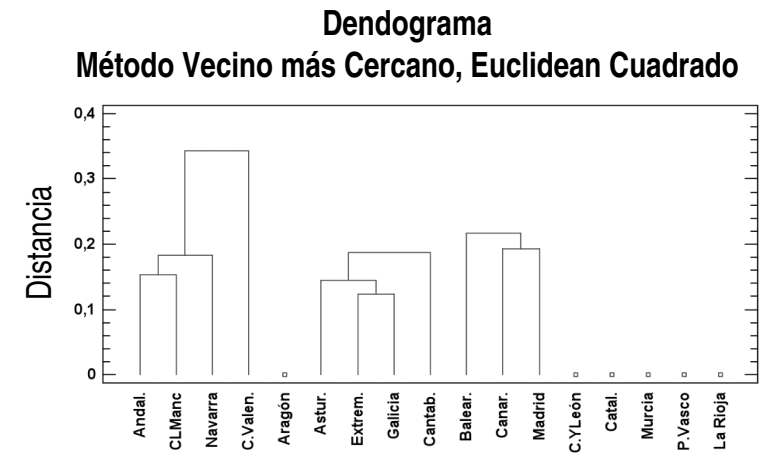

\section{Tabla 4. Resultados cluster 2007. Nivel de autoempleo en Economía Social de las CC.AA.}

\begin{tabular}{|c|c|c|c|c|c|c|c|c|c|}
\hline Cluster 2007 & 1 & 2 & 3 & 4 & 5 & 6 & 7 & 8 & 9 \\
\hline CC.AA. & $\begin{array}{c}\text { Andalucía } \\
\text { C.-La Mancha } \\
\text { Navarra } \\
\text { C.Valenciana }\end{array}$ & Aragón & $\begin{array}{c}\text { Asturias } \\
\text { Extremadura } \\
\text { Galicia } \\
\text { Cantabria }\end{array}$ & $\begin{array}{c}\text { Baleares } \\
\text { Canarias } \\
\text { Madrid }\end{array}$ & C.y León & Cataluña & Murcia & P. Vasco & La Rioja \\
\hline $\begin{array}{l}\text { Media } n^{0} \text { autónomos cooperativas } \\
\text { por cada } 1000 \text { ocupados }\end{array}$ & 3,12 & 2,94 & 1,01 & 0,59 & 2,14 & 3,31 & 5,88 & 33,61 & 3,91 \\
\hline $\begin{array}{l}\text { Media } n^{\circ} \text { cooperativas } \\
\text { por cada } 1000 \text { empresas }\end{array}$ & 3,32 & 3,79 & 1,22 & 0,68 & 2,08 & 5,30 & 7,44 & 3,98 & 2,39 \\
\hline $\begin{array}{l}\text { Media } n^{0} \text { autónomos } \\
\text { por cada } 1000 \text { ocupados }\end{array}$ & 107,42 & 138,86 & 138,74 & 91,79 & 188,29 & 105,83 & 111,39 & 101,69 & 133,29 \\
\hline Medias nacionales: & & 105 & $\begin{array}{r}\operatorname{vas} \times 1000 \\
n^{0}\end{array}$ & ipados = & oo ocup & $\begin{array}{l}\text { operati } \\
=119,9\end{array}$ & 1000 & esas $=2,6$ & \\
\hline
\end{tabular}

CIRIEC-España, Revista de Economía Pública, Social y Cooperativa 
Gráfico 8. Dendograma obtenido para 2013 a partir de las variables " $n$ ' autónomos en cooperativas por cada 1.000 ocupados", " $n$ " de cooperativas por cada 1.000 empresas" y " $n$ ' de autónomos propiamente dicho por cada 1.000 ocupados", de las distintas CC.AA.

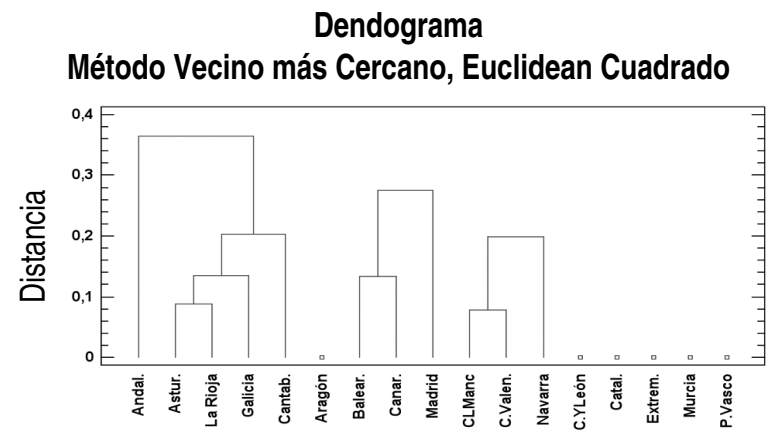

\section{Tabla 5. Resultados cluster 2013. Nivel de autoempleo en Economía Social de las CC.AA.}

\begin{tabular}{|c|c|c|c|c|c|c|c|c|c|}
\hline Cluster 2013 & 1 & 2 & 3 & 4 & 5 & 6 & 7 & 8 & 9 \\
\hline CC.AA. & $\begin{array}{l}\text { Andalucía } \\
\text { Asturias } \\
\text { La Rioja } \\
\text { Galicia } \\
\text { Cantabria }\end{array}$ & Aragón & $\begin{array}{c}\text { Baleares } \\
\text { Canarias } \\
\text { Madrid }\end{array}$ & $\begin{array}{c}\text { C.La Mancha } \\
\text { C.Valenciana } \\
\text { Navarra }\end{array}$ & C.y León & Cataluña & Extrem. & Murcia & P. Vasco \\
\hline $\begin{array}{l}\text { Media } n^{0} \text { autónomos cooperativas } \\
\text { por cada } 1000 \text { ocupados }\end{array}$ & 1,63 & 3,35 & 0,75 & 4,37 & 2,08 & 4,05 & 1,51 & 6,44 & 38,82 \\
\hline $\begin{array}{l}\text { Media } n^{0} \text { cooperativas } \\
\text { por cada } 1000 \text { empresas }\end{array}$ & 1,48 & 3,82 & 0,82 & 3,92 & 1,79 & 5,66 & 1,60 & 7,65 & 4,54 \\
\hline $\begin{array}{l}\text { Media } n^{0} \text { autónomos por } \\
\text { cada } 1000 \text { ocupados }\end{array}$ & 134,22 & 135,39 & 94,02 & 107,26 & 193,71 & 110,20 & 164,45 & 111,88 & 101,04 \\
\hline Medias nacionales: & & omos co & rativas $\times 10$ & $\begin{array}{l}\text { ocupados }=4,6 \\
n^{\circ} \text { autónomos } x\end{array}$ & Oocupa & $\begin{array}{l}l^{\circ} \text { cooperatil } \\
s=123,03\end{array}$ & $\times 1000$ & npresa & \\
\hline
\end{tabular}

Tanto para 2007 como para 2013 se han obtenido 9 grupos, lo que demuestra que los diferentes territorios cuentan con heterogeneidades considerables que hacen poco posible establecer un modelo global sobre el comportamiento del autoempleo en su conjunto (colectivo e individual) con respecto a los resultados obtenidos (Gráficos 8 y 9). A pesar de esta dificultad, se pueden señalar los siguientes aspectos comunes: 
1. Se ha producido un incremento del autoempleo en general (tanto colectivo como individual), aunque no de manera homogénea.

2. País Vasco y Murcia presentan comportamientos particulares (siendo las únicas comunidades que conforman el cluster al que pertenece cada una), no asemejándose a ninguna otra región. Estas CC.AA. destacan por la importancia considerable que presenta el autoempleo colectivo (no ocurriendo lo mismo con el autoempleo individual), situándose sus valores muy por encima de las medias españolas tanto en 2007 como en 2013. Lo contrario le ocurre a la comunidad autónoma de Castilla y León, que siendo también el único miembro del cluster 2 para ambos años, presenta un alto grado de autoempleo individual, con el mayor valor de todo el territorio español.

3. Existe un grupo de CC.AA. formado por Baleares, Canarias y Madrid que se mantienen en niveles muy bajos de autoempleo en los dos años objeto de estudio, con unas medias de grupo muy inferiores a las nacionales.

En general, no se puede plantear un patrón de comportamiento homogéneo ya que puede existir fuerte autoempleo tanto en CC.AA. con una situación económica muy favorable, como en otras con una situación económica más adversa. Además, este autoempleo puede darse, como se va a especificar posteriormente, bien sobre el componente colectivo, el individual, 0 ambos. A esto hay que añadir que este autoempleo se genera en distintos sectores económicos según la región, por lo que es importante considerar los factores territoriales internos y/o externos, el sistema productivo local y el marco institucional, entre otros, para comprender el comportamiento en cada Comunidad.

Dada esta heterogeneidad que presentan las distintas CC.AA. y la necesidad de profundizar en los comportamientos más destacables, se detalla a continuación el análisis de los componentes del autoempleo, -colectivo e individual-, para los años 2007 y 2013.

- Autoempleo colectivo 2007 y 2013:

\section{Gráfico 9. Dendograma obtenido para 2007 a partir de las variables " $n$ ' autónomos en cooperativas por cada 1.000 ocupados" y "n' de cooperativas por cada 1.000 empresas", de las distintas CC.AA.}

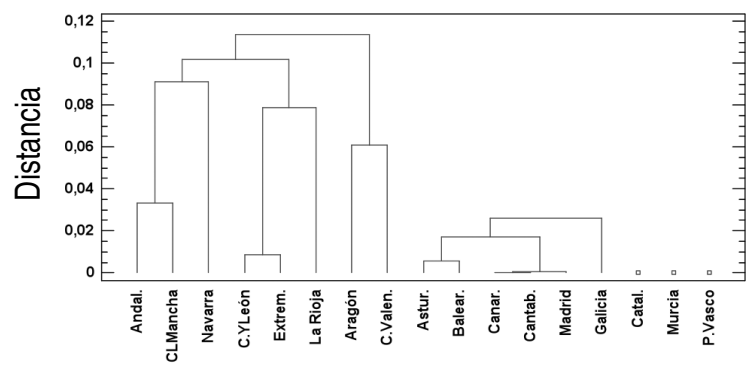


Gráfico 10. Dendograma obtenido para 2013 a partir de las variables "n` autónomos en cooperativas por cada 1000 ocupados" y "n de cooperativas por cada 1.000 empresas", de las distintas CC.AA.

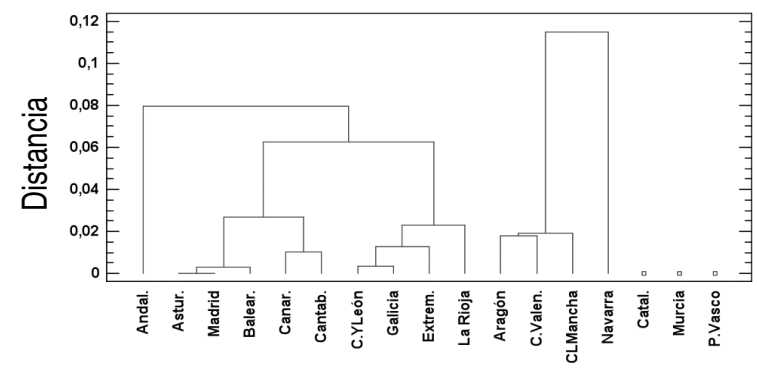

\section{Tabla 6. Resultados cluster 2007. Nivel de autoempleo colectivo de las CC.AA}

\begin{tabular}{|c|c|c|c|c|c|}
\hline Cluster 2007 & 1 & 2 & 3 & 4 & 5 \\
\hline CC.AA. & $\begin{array}{c}\text { Andalucía } \\
\text { C.L.Mancha } \\
\text { Navarra } \\
\text { C. y León } \\
\text { Extremadura } \\
\text { La Rioja } \\
\text { Aragón } \\
\text { C.Valenciana }\end{array}$ & $\begin{array}{c}\text { Asturias } \\
\text { Baleares } \\
\text { Canarias } \\
\text { Cantabria } \\
\text { Madrid } \\
\text { Galicia }\end{array}$ & Cataluña & Murcia & P. Vasco \\
\hline Media $n^{0}$ autónomos cooperativas por cada 1000 ocupados & 2,89 & 0,70 & 3,31 & 5,89 & 33,61 \\
\hline Media $n^{\circ}$ cooperativas por cada 1000 empresas & 2,94 & 0,83 & 5,31 & 7,44 & 3,98 \\
\hline Medias nacionales: & \multicolumn{5}{|c|}{$\begin{array}{c}n^{\circ} \text { autónomos cooperativas } x 1000 \text { ocupados }=4,12 \\
n^{\circ} \text { cooperativas } x 1000 \text { empresas }=2,65\end{array}$} \\
\hline
\end{tabular}




\section{Tabla 7. Resultados cluster 2013. Nivel de autoempleo colectivo de las CC.AA.}

\begin{tabular}{|c|c|c|c|c|c|}
\hline Cluster 2013 & 1 & 2 & 3 & 4 & 5 \\
\hline CC.AA. & $\begin{array}{l}\text { Andalucía } \\
\text { Asturias } \\
\text { Madrid } \\
\text { Baleares } \\
\text { Canarias } \\
\text { Cantabria } \\
\text { C.y León } \\
\text { Galicia } \\
\text { Extremadura } \\
\text { La Rioja }\end{array}$ & $\begin{array}{c}\text { Aragón } \\
\text { C.Valenciana } \\
\text { C.La Mancha } \\
\text { Navarra }\end{array}$ & Cataluña & Murcia & P. Vasco \\
\hline Media $n^{\circ}$ autónomos cooperativas por cada 1000 ocupados & 1,40 & 4,12 & 4,05 & 6,44 & 38,82 \\
\hline Media $n^{\circ}$ cooperativas por cada 1000 empresas & 1,32 & 3,89 & 5,66 & 7,65 & 4,54 \\
\hline Medias nacionales: & $n^{\circ} a b$ & $\begin{array}{l}\text { omos coopera } \\
\text { cooperativas } x\end{array}$ & $\begin{array}{l}\text { as } \times 1000 \\
00 \text { empre }\end{array}$ & $\begin{array}{l}\text { upados }= \\
s=2,74\end{array}$ & \\
\hline
\end{tabular}

Tanto para 2007 como 2013, se han obtenido 5 grupos de CC.AA. En el dendograma para 2007 (Gráfico 9) destaca la heterogeneidad entre los miembros del primer grupo (formado por las comunidades de Andalucía, Castilla La Mancha, Navarra, Castilla y León, Extremadura, La Rioja, Aragón y Comunidad Valenciana), con una notable distancia entre ellos. Es decir, que aunque todas estas regiones forman un cluster, manifiestan diferencias considerables entre ellas. No ocurre lo mismo con el cluster 2 (representado por Asturias, Baleares, Canarias, Cantabria, Madrid y Galicia), en el que la distancia entre las regiones es mucho menor presentando una mayor homogeneidad.

Con respecto a las medias nacionales, el autoempleo colectivo (en términos relativos) ha mejorado tras el periodo de crisis (incrementándose el número de autónomos en cooperativas un 13,83\% y el número de cooperativas -con la plantilla de trabajadores íntegra en el régimen de autónomos de la Seguridad Social- un 3,39\%) (Tablas 6 y 7 ).

Las comunidades más destacables son Murcia y País Vasco que, como ya se ha comprobado anteriormente, mantienen un nivel de autoempleo colectivo (en términos relativos) elevado antes y durante la crisis.

El comportamiento de Cataluña también es destacable dado que es otra región que forma un único cluster tanto en 2007 como en 2013 y, sin embargo, a diferencia de País Vasco, los datos apuntan a que las empresas cooperativas de autoempleo colectivo son de pequeña dimensión (el número de 
autónomos está rozando la media española, mientras que el número de empresas sí supera el valor medio).

Con respecto al grupo formado por Aragón, Comunidad Valenciana, Castilla La Mancha y Navarra (Tablas 6 y 7), con la crisis, ha reducido sus divergencias apreciándose una menor distancia entre los miembros del grupo (Gráfico 10). Aquí destaca la comunidad de Navarra que se muestra con un comportamiento más atípico presentando la mayor distancia con respecto al resto de comunidades.

Las comunidades de Asturias, Baleares, Canarias, Cantabria y Madrid se sitúan en todo momento en un nivel de autoempleo colectivo poco significativo, a las que se unen Andalucía, Castilla y León, Extremadura y La Rioja en 2013, perdiendo posición relativa.

Se ha producido una serie de cambios entre los miembros de los grupos 1 y 2 en 2013 con respecto a 2007. En base a esto, se podría sostener que estas comunidades, a diferencia de Cataluña, Murcia y País Vasco, han presentado una mayor sensibilidad en el periodo de crisis en lo que respecta al autoempleo colectivo en términos relativos.

Otro aspecto a resaltar es que el cluster 1 , en 2013 con una crisis ya consolidada, ha reducido la heterogeneidad entre las regiones, siendo ahora menor la distancia entre éstas.

- Autoempleo individual 2007 y 2013:

\section{Gráfico 11. Dendograma obtenido para 2007 a partir de la variable "n' de autónomos propiamente dicho por cada 1.000 ocupados" de las distintas CC.A.A.}

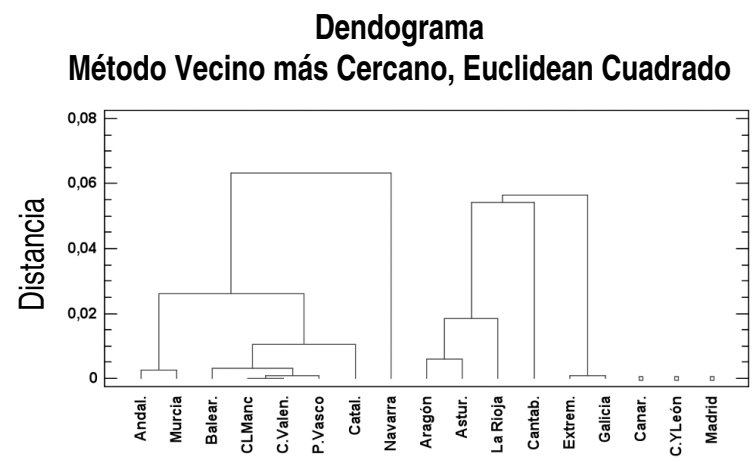


Gráfico 12. Dendograma obtenido para 2013 a partir de la variable "n' de autónomos propiamente dicho por cada 1.000 ocupados" de las distintas CC.A.A.

Dendograma

Método Vecino más Cercano, Euclidean Cuadrado

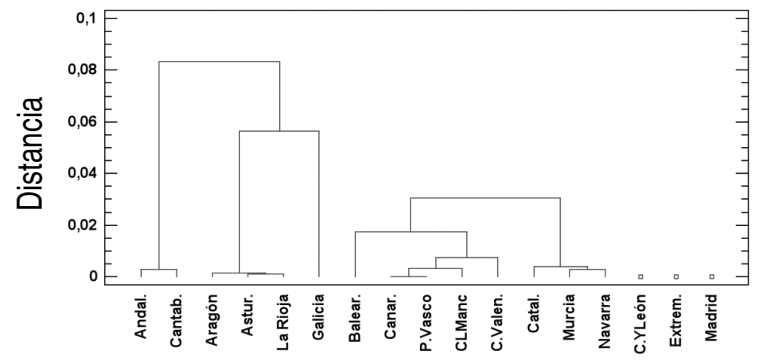

Con la consolidación de la crisis, la media nacional del número de autónomos por cada 1000 ocupados ha aumentado pasando de 119,9 (Tabla 8) a 123 (Tabla 9) planteándose como una posible respuesta ante el desempleo masivo y persistente.

\section{Tabla 8. Resultados cluster 2007. Nivel de autoempleo individual de las CC.AA.}

\begin{tabular}{|c|c|c|c|c|c|}
\hline Cluster 2007 & 1 & 2 & 3 & 4 & 5 \\
\hline CC.AA. & $\begin{array}{c}\text { Andalucía } \\
\text { Baleares } \\
\text { C.La Mancha } \\
\text { Cataluña } \\
\text { C.Valenciana } \\
\text { Murcia } \\
\text { Navarra } \\
\text { P.Vasco }\end{array}$ & $\begin{array}{c}\text { Aragón } \\
\text { Asturias } \\
\text { Cantabria } \\
\text { Extremadura } \\
\text { Galicia } \\
\text { La Rioja }\end{array}$ & Canarias & C. y León & Madrid \\
\hline Media $n^{\circ}$ autónomos por cada 1000 ocupados & 106,5 & 137,9 & 91,8 & 188,3 & 80,4 \\
\hline
\end{tabular}




\section{Tabla 9. Resultados cluster 2013. Nivel de autoempleo individual de las CC.AA.}

\begin{tabular}{|c|c|c|c|c|c|}
\hline Cluster 2013 & 1 & 2 & 3 & 4 & 5 \\
\hline CC.AA. & $\begin{array}{c}\text { Andalucía } \\
\text { Aragón } \\
\text { Asturias } \\
\text { Cantabria } \\
\text { Galicia } \\
\text { La Rioja }\end{array}$ & $\begin{array}{c}\text { Baleares } \\
\text { Canarias } \\
\text { C.La Mancha } \\
\text { Cataluña } \\
\text { C.Valenciana } \\
\text { Murcia } \\
\text { Navarra } \\
\text { P.Vasco }\end{array}$ & C.y León & Extremadura & Madrid \\
\hline Media $n^{0}$ autónomos por cada 1000 ocupados & 134,4 & 105,5 & 193,7 & 164,4 & 83,2 \\
\hline
\end{tabular}

A partir del análisis anterior, se ponen de manifiesto diferentes comportamientos en cuanto a la evolución del autoempleo individual antes y desde el inicio de la crisis, identificándose comunidades que mantienen sistemáticamente su alto o bajo nivel de autoempleo en los años objeto de estudio, mientras otras modifican su tendencia, lo que puede ser debido a su situación y sus especificidades territoriales. En este sentido se puede señalar lo siguiente:

1. Castilla y León ha mantenido el nivel más alto de autoempleo individual y Madrid el más bajo, tanto antes como tras la consolidación de la crisis.

2. Otro grupo de Comunidades Autónomas siempre ha mantenido niveles bajos tanto en 2007 como en 2013 (Baleares, Castilla La Mancha, Cataluña, Comunidad Valenciana, Murcia, Navarra y País Vasco).

3. Aragón, Asturias, Cantabria, Galicia y La Rioja (cluster 2 y 1 en 2007 y 2013, respectivamente) han conservado un nivel de autoempleo individual relativo por encima de la media y a las que en 2013, se une Andalucía, región que en 2007 se asemejaba más a las de niveles bajos. En esta línea, Extremadura es otra comunidad que mejora su posición pasando de una media de grupo del $13,78 \%$ al $16,44 \%$ y manteniendo por tanto, e incluso mejorando, un nivel elevado en el grado de autoempleo individual relativo.

Tras los análisis realizados, en primer lugar y considerando el autoempleo en general (colectivo e individual), existen un grupo de CC.AA. en las que el nivel es poco significativo, no presentando además, apenas, ninguna variación con la crisis. Es el caso de Baleares, Canarias y Madrid, estando la primera y la última entre las regiones más avanzadas del país. 
En segundo lugar, existe una serie de CC.AA. que consigue mantenerse e incluso mejorar, y que podría deberse bien a haber apostado por el autoempleo como respuesta a la crisis, bien a que ya previamente contaban con una cultura emprendedora sólida. Es el caso de Cataluña, Comunidad Valenciana, Murcia, País Vasco y Navarra en autoempleo colectivo; y de Andalucía, Extremadura y Castilla y León, respecto al individual. Estas CC.AA. presentan diferente grado de desarrollo entre ellas.

Dos comportamientos opuestos son el de Cataluña, por un lado, y el de Andalucía y Extremadura, por otro:

- La comunidad de Cataluña presenta a lo largo del periodo un nivel de autoempleo colectivo (relativo) importante, mientras que en el individual sus valores están por debajo de la media.

- Andalucía y Extremadura con la crisis empeoran su nivel de autoempleo colectivo, sin embargo, en el individual mejoran.

A partir de los análisis anteriores se han detectado importantes divergencias regionales, no existiendo grupos de CC.AA. con un determinado patrón de comportamiento respecto al autoempleo según la situación económica del territorio: existe fuerte autoempleo tanto en comunidades avanzadas,-por ejemplo País Vasco-, como en otras con una situación económica menos favorable, siendo el caso de Andalucía o Extremadura. Madrid, por el contrario, no cuenta con significativos niveles de autoempleo, presentando esta región una situación económica de las más favorables.

A su vez, dentro de las CC.AA. que tienen en común una significativa importancia en autoempleo colectivo, hay que resaltar que éste presenta relevantes diferencias entre las regiones que son más avanzadas económicamente (por ejemplo Cataluña, País Vasco o Navarra) y aquéllas otras que presentan importante atraso relativo o se han visto muy afectadas por la crisis (como es el caso de Murcia) (Gráfico 6), en lo que se refiere al papel que desempeña dentro de la economía.

En este sentido, Murcia destaca por concentrar un 2,5\% de sus trabajadores autónomos en cooperativas en el sector primario, porcentaje superior a la media nacional $(1,16 \%)$, mientras que, por ejemplo, País Vasco o Cataluña lo hacen en el sector industrial con un 50,29\% y $46,40 \%$ respectivamente, frente al $43,83 \%$ de la media nacional. Se puede decir que, en estas comunidades, el autoempleo colectivo está dirigido hacia sectores que tradicionalmente han estado muy presentes en sus respectivos sistemas productivos territoriales.

En lo que respecta al autoempleo individual, lo más destacable es señalar la importancia de las CC.AA. de Castilla y León y Extremadura que, si bien no son representativas del autoempleo colectivo, sí mantienen elevados niveles de autoempleo individual y además dirigido hacia un sector económico importante dentro de sus sistemas productivos: el sector primario. 
Dado que el autoempleo en buena parte de las CC.AA. se ha dirigido a las actividades con una importancia relativa en sus sistemas productivos, esto podría ser una evidencia de que la Economía Social, a través del autoempleo, está capacitada para responder a las necesidades locales de cada territorio. Un ejemplo de esto podría encontrarse en las comunidades de Murcia y País Vasco.

En la Región de Murcia se han elaborado extensos programas y subvenciones destinadas a la Economía Social y al emprendimiento. En 2014 se contó con siete programas destinados a subvencionar distintos ejes de la Economía Social10:

1. Empleo en cooperativas y sociedades laborales. Subvenciones destinadas a aquellas que incorporen en sus plantillas a socios-trabajadores.

2. Subvenciones a aquellas entidades de Economía Social que hagan ampliación del capital social.

3. Subvenciones a la difusión y el fomento de la Economía Social por parte de las organizaciones empresariales del sector.

4. Ayudas para fomentar la formación y consolidación de las organizaciones representativas 0 asociativas de la Economía Social.

5. Asistencia técnica para constituir nuevas empresas.

6. Ayudas para inversiones en activos fijos materiales.

7. Subvenciones a las Universidades Públicas que lleven a cabo actividades de investigación, docencia y difusión del sector.

Esto podría ser solo un ejemplo de la amplia dedicación de los actores de la región para consolidar el sector. Desde fomentar la creación de empleo en la Economía Social hasta su difusión y conocimiento por parte de las universidades públicas, en la comunidad de Murcia parece que se están haciendo esfuerzos por proporcionar mayor visibilidad y protagonismo a la Economía Social.

En lo que respecta a País Vasco, comunidad que destaca por sus niveles de autoempleo colectivo, cuenta con el grupo Mondragón, toda una red de empresas de Economía Social y que, aunque comenzó sus andaduras en el ámbito industrial, ha ampliado significativamente su campo de actividad dedicándose también al ámbito financiero educativo y/o de investigación. Este amplio abanico de actividades es el resultado de su preocupación por las necesidades locales a las que han sabido dar respuesta a través de empresas autogestionadas y en redes (Sarasua, 2008).

Atendiendo a la dimensión empresarial de las cooperativas de estas dos regiones (Murcia y País Vasco) con un notable autoempleo colectivo, se observa una diferencia evidente entre ambas: en País Vasco el tamaño de estas empresas es mayor, dado que concentran a sus trabajadores autónomos (38,82 por cada mil ocupados frente a los 6,44 de Murcia) en un menor número de cooperativas (4,54 por cada mil empresas cooperativas frente a las 7,65 de Murcia). 
Aunque merece una atención más profunda, se podría argumentar que en País Vasco el autoempleo colectivo -el emprendimiento en grupo- es de mayor intensidad que en otras regiones, lo que a su vez podría ser indicativo de que las interrelaciones entre los distintos agentes territoriales presentes en esta región son de mayor calado que en otras.

Estas dos regiones (Murcia y País Vasco) han abordado la Economía Social de manera diferente; pero lo más significativo a destacar, según la importancia del binomio "Economía Social-Desarrollo Territorial" planteado en este trabajo, es que ambas comunidades lo han hecho atendiendo a sus necesidades locales y como una forma de respuesta a las mismas, a partir de sus realidades territoriales.

\section{6.- Conclusiones}

El mayor reflejo del profundo impacto de la crisis actual en España es el rápido y diferencial crecimiento del desempleo llegando a cifras del 26\% en 201311, según la Encuesta de Población Activa del Instituto Nacional de Estadística. Una alternativa que ayude a mitigar esto podría ser la creación de empleo mediante empresas autogestionadas -a través del autoempleo- lo que se está fomentando desde diferentes ámbitos institucionales públicos y privados, pero con diferente grado de intensidad. Por ello, es necesario el diseño de políticas para el fomento del autoempleo y de la Economía Social, tanto de carácter general como específico para cada territorio, a partir de diagnósticos territoriales, con objeto de mejorar sus resultados.

La Economía Social está consolidándose como una respuesta, como una alternativa posible, menos sensible y que amortigua más las perturbaciones cíclicas, dejando de ser, progresivamente, una actividad subsidiaria y residual. Esta mayor resistencia se ha podido comprobar al analizar la evolución seguida en el periodo 1999-2013 por el autoempleo colectivo y el individual, -integrantes de la Economía Social-, en valores relativos (en relación al número de ocupados totales).

La crisis también ha puesto de manifiesto la necesidad de apostar por modelos productivos más sostenibles, sociales y respetuosos en todos los aspectos. En este sentido, las empresas de Economía Social pueden contribuir a ello dado los principios y valores sobre los que basan su funcionamiento y la relación que presentan con el territorio en el que desarrollan su actividad. $23,70 \%$

11.- Según datos de la Encuesta de Población Activa (EPA), en el cuarto trimestre de 2014 la cifra de la tasa de paro se situaba en el 
Esta relación entre Economía Social y territorio y, sobre todo, la necesidad de la creación de empleo, llevan a plantear el autoempleo en Economía Social como una aportación positiva a la coyuntura actual. El autoempleo referido aquí es considerado como integrante de la Economía Social por su condición de empresa de participación en la que estos trabajadores intervienen de manera activa en los flujos y operaciones empresariales.

En este trabajo, por un lado, se ha identificado el distinto comportamiento seguido por las CC.AA. en cuanto a autoempleo (relativo) generado en el ámbito de la Economía Social, tanto colectivo como individual, para los años objeto de estudio; $y$, por otro, aplicando el análisis cluster, se concluye que no puede establecerse un patrón de comportamiento determinado, homogéneo, para el conjunto de regiones españolas en relación a su situación económica, existiendo territorios con un importante grado de autoempleo colectivo y/o individual y otros en el que la existencia de esta figura empresarial es escasa, no regidos por pautas comunes.

En este sentido, es de destacar, por un lado, la existencia de un grupo de CC.AA. que han mantenido niveles bajos de autoempleo en términos relativos (tanto colectivo como individual) no presentando apenas variaciones ante la crisis y que está formado por Baleares, Canarias y Madrid. Por otro lado, existe una serie de regiones que se mantienen e incluso mejoran sus niveles de autoempleo, aunque presentan diferentes situaciones económicas: Cataluña, Comunidad Valenciana, Murcia, País Vasco y Navarra en el autoempleo colectivo y Andalucía, Extremadura y Castilla y León, en el individual. El comportamiento del autoempleo en estas regiones podría justificarse porque, 0 bien éstas han realizado esfuerzos por fomentarlo y desarrollarlo como respuesta a la crisis, o bien a que previamente ya contaban con una cultura emprendedora sólida.

La diversidad de grupos obtenidos podría deberse, en general, a la relación de la Economía Social con el territorio y, en particular, a la relación del autoempleo generado por estas entidades partiendo y atendiendo a la realidad específica de cada marco territorial. Estas empresas surgen de los recursos endógenos de cada territorio, vinculadas a sus sistemas productivos locales, pudiendo llegar a desempeñar un significativo papel como elemento de dinamización y de desarrollo territorial. En esta línea, por ejemplo, Murcia destaca por concentrar trabajadores autónomos en cooperativas en una proporción superior a la media nacional en el sector primario, mientras que, País Vasco o Cataluña lo hacen en el sector industrial, presentando además diferencias en la dimensión empresarial. En estas regiones, el autoempleo colectivo se ha dirigido tradicionalmente hacia sectores muy presentes en sus respectivos sistemas productivos territoriales.

El requerimiento de nuevos modelos productivos más sostenibles, la mayor resistencia de las empresas de Economía Social, la adaptación de estas empresas a los sistemas productivos de cada territorio y la heterogeneidad manifestada en los análisis clusters realizados entre las regiones, conducen a la necesidad de establecer políticas que fomenten el autoempleo como factor de desarrollo "desde abajo". Para mejorar sus resultados debe partirse de un diagnóstico territorial que se aplique al diseño, gestión, ejecución y evaluación de esas políticas. Es necesario conocer las características 
propias de cada territorio, su dotación de recursos endógenos, su capacidad de vertebración interna y externa, la participación activa de sus actores territoriales, para que, a partir de un diagnóstico completo y de la proyección de sus potencialidades, se puedan diseñar y aplicar medidas específicas que garanticen la obtención de resultados más eficientes, sobre todo en lo que se refiere al emprendimiento a través de empresas de participación. La Economía Social se presenta así como un agente endógeno de dinamización del desarrollo territorial sostenible.

A partir de este trabajo se abren futuras líneas de investigación para intensificar el conocimiento de la relación entre la Economía Social y el Desarrollo Territorial, introduciendo un mayor número de variables explicativas que puedan contribuir a la justificación del diferente comportamiento regional.

\section{7.- Bibliografía}

ALBURQUERQUE, F. (2007): "Desarrollo económico y territorio: enfoques teóricos relevantes y reflexiones derivadas de la práctica". En: M. García Docampo, Perspectivas Teóricas en Desarrollo Local, editorial Netbiblo, La Coruña, 59-75.

BAREA, J. (1990): "Concepto y agentes de la economía social”, CIRIEC-España, Revista de Economía Pública, Social y Cooperativa, 8, 119-117.

BAREA, J. (2003): "Constitución y nueva Economía Social", CIRIEC-España, Revista de Economía Pública, Social y Cooperativa, 47, 137-148.

BAREA, J. (2008): "El concepto científico de economía social desde la perspectiva actual", Temas para el Debate, 167, Octubre, ISSN: 1134-6574.

CALDERÓN, B. \& CALDERÓN, M.J. (2012): "Cómo afrontan la crisis las cooperativas en España: comparativa de trayectorias laborales a partir de la Muestra Continua de Vidas Laborales", CIRIECEspaña, Revista de Economía Pública, Social y Cooperativa, 76, 5-26.

CECOP-CICOPA (2011): "A pesar de las dificultades, las cooperativas de industria y servicios, resisten a la crisis y sus consecuencias", Tercer informe anual sobre la crisis, Junio 2011.

CHAVES, R., MONZÓN, J.L., PÉREZ DE URALDE, J.M. \& RADRIGÁN, M. (2013): "La Economía Social en clave internacional. Cuantificación, reconocimiento institucional y visibilidad social en Europa, Iberoamérica y Norte de África", REVESCO, Revista de Estudios Cooperativos, 112, 122150. 
COMITÉ DE LAS REGIONES EUROPEAS (2002): Dictamen sobre el tema "Asociaciones entre las autoridades locales y regionales y las organizaciones socioeconómicas: contribución al empleo, al desarrollo local y a la cohesión social". http://bookshop.europa.eu/es/dictamen-sobre-el-temaasociaciones-entre-las-autoridades-locales-y-regionales-y-las-organizaciones-socioecon-micascontribuci-n-al-empleo-al-desarrollo-local-y-a-la-cohesi-n-social-pbGFHA02007/ (Consultado el 7-07-2014).

CORNFORTH, C. \& THOMAS, A. (1995): "Les cooperatives de travail au Rouyaume Uni. Declin ou croissance?", Revue de Etudes Cooperatives, Mutualistee et Associatives, 255, 53.

CRUZ, T. \& TORRES, L. (2003): "El autoempleo: una opción laboral al finalizar la educación obligatoria".http://www.juntadeandalucia.es/averroes/ emprender/documentos/autoempleoacabar.pdf (Consultado el 5-07-2014).

DE CASTRO, M. (2003): "La Economía Social como agente económico: necesidad de su participación en la interlocución social", CIRIEC-España, Revista de Economía Pública, Social y Cooperativa, 47, 41-57.

DÍAZ, F. (2000): "Desempleo y cooperativismo", CIRIEC-España, Revista de Economía Pública, Social y Cooperativa, 35, 161-176.

DÍAZ, M. \& MARCUELLO, C. (2010): "Impacto económico de las cooperativas. La generación de empleo en las sociedades cooperativas y su relación con el PIB", CIRIEC-España, Revista de Economía Pública, Social y Cooperativa, 67, 23-44.

GARCÍA, M. (2002): Autoempleo y trabajo asociado. El trabajo en la Economía Social, Servicio de Publicaciones de la Universidad de Córdoba.

GARCÍA-GUTIÉRREZ, C. \& FERNÁNDEZ, J. (2005): "El empresario individual: situación actual y propuesta de actuación futuras", CIRIEC-España, Revista de Economía Pública, Social y Cooperativa, 52, 201-217.

GARCÍA-GUTIÉRREZ, C., LEJARRIAGA, G., BEL, P., FERNÁNDEZ, J. \& MARTíN, S. (2013): "Empresas individuales y trabajo autónomo: evolución y previsiones". En: G. Lejarriaga, S. Martín y A. Muñoz (dirs.), 40 años de historia de las Empresas de Participación, editorial Verbum, Madrid, 342-366.

GRÁVALOS, M.A. \& POMARES, I. (2001): "Cooperativas, desempleo y efecto refugio", REVESCO, Revista de Estudios Cooperativos, 74, 69-84.

GUERRERI, G., NAZZARO, O. \& ZEVI, A. (1992): "La economía social en Italia". En: Monzón, J.L. y Defourny, J. (Dirs.), Economía Social, entre economía capitalista y economía pública, CIRIECEspaña editorial y Ministerio de Trabajo y Seguridad Social, Valencia, 157-198.

INGLADA, M.E. \& SASTRE, J.M. (2014): "Reflexiones sobre la globalización, pobreza y desarrollo: incidencia en las organizaciones de economía social", REVESCO, Revista de Estudios Cooperativos, 116, 160-179. 
LEJARRIAGA, G., BEL, P. \& MARTÍN, S. (2013): "El emprendimiento colectivo como salida laboral de Ios jóvenes: análisis del caso de las empresas de trabajo asociado", REVESCO, Revista de Estudios Cooperativos, 112, 36-65.

MELIÁN, A. \& CAMPOS, V. (2010): "Emprendedurismo y economía social como mecanismos de inserción sociolaboral en tiempos de crisis", REVESCO, Revista de Estudios Cooperativos, 100, 4367.

MARTíN, S. \& LEJARRIAGA, G. (2011): "Las empresas de participación de trabajo asociado ante los desafíos del futuro en un contexto de crisis económica: propuestas de actuación", CIRIECEspaña, Revista de Economía Pública, Social y Cooperativa, 56, 9-24.

MONZÓN, J. L. (2006): "Economía Social y conceptos afines: fronteras borrosas y ambigüedades conceptuales del Tercer Sector", CIRIEC-España, Revista de Economía Pública, Social y Cooperativa, 56, 9-24.

MONZÓN, J.L. (Coord.) (2010): Las empresas de trabajo asociado en España. Evolución reciente y perspectivas, CIRIEC-España editorial, Valencia.

ROMÁN, C. (2010): "Las cooperativas españolas y los ciclos económicos: una primera aproximación, 1942-2002", Asociación Española de Historia Económica (AEHE), Documentos de trabajo nº 1013.

SANCHIS, J.R. \& CAMPOS, V. (2005): "Inserción Sociolaboral, Economía Social y Desarrollo Local. Estudio empírico sobre la realidad actual del Agente de Empleo y Desarrollo Local en España", CIRIEC-España, Revista de Economía Pública, Social y Cooperativa, 52, 279-306.

SALA, M., FARRÉ, M. \& TORRES, T. (2014): "Un análisis del comportamiento cíclico de las cooperativas y sociedades laborales españolas y de su relación con la actividad económica", REVESCO, Revista de Estudios Cooperativos, 115, 7-29.

SARASUA, J. (2008): "Mondragón en un nuevo siglo: síntesis reflexiva de la experiencia cooperativa". En: L. Altuna Gabilondo (coord.), La experiencia cooperativa de Mondragón: una síntesis general, Lanki - Mondragon Unibertsitatea, Gipuzkoa.

TOMÁS-CARPI, J.A. (1997): "La economía social en un mundo en transformación", CIRIEC-España, Revista de Economía Pública, Social y Cooperativa, 25, 83-115.

TOMÁS-CARPI, J. (2008): "El desarrollo local sostenible en clave estratégica", CIRIEC-España, Revista de Economía Pública, Social y Cooperativa, 61, 73-101.

VÁZQUEZ, A. (1999): Desarrollo, redes e innovación: lecciones sobre desarrollo endógeno, Ediciones Pirámide, Madrid.

VÁZQUEZ, A. (2005): Las nuevas fuerzas del desarrollo, Antonio Bosch, Barcelona. 